\title{
The Multidimensionality of Consumption: Energy Lifestyles
}

The previous chapter concluded by considering the factors that shape the total greenhouse gas ( $\mathrm{GHG}$ ) emissions of our respondents. The current chapter ${ }^{1}$ extends this view by explicitly considering the multidimensionality of behavior. It considers the energy demand in the considered six areas of life (housing, mobility, consumption of goods, diet, leisure activities, and information) and combines them into unique patterns of energy consumption - that is, the "Energy Lifestyles" of the Austrian population.

It thus enhances the previous understanding of Energy Lifestyles in Austria in a specific way. While some earlier studies of survey data obtained implausible or inconsistent results by drawing conclusions from the respondents' lifestyles (based on psychological characteristics) on their (energy) behavior (Hierzinger et al., 2011; Bohunovsky et al., 2011), the current analysis starts from the energy demands of the respondents-that is, energy-related lifestyles are identified by clustering respondents according to their annual primary energy demands in the different areas of social life.

By identifying and analyzing a number of distinctive Energy Lifestyles, this chapter provides an overview of the quality and quantity of energyrelated behavioral patterns in Austria. It shows that the overall lifestylerelated energy demands of the identified groups are composed in entirely

${ }^{1}$ Lead author: Stephan Schwarzinger. This chapter is based on the lead author's doctoral thesis.

(C) The Author(s) 2022

M. Hadler et al., Surveying Climate-Relevant Behavior, https://doi.org/10.1007/978-3-030-85796-7_6 
different ways and that an "average Energy Lifestyle" is the exemption. Using this classification as a basis, it also discusses target group-oriented policy interventions.

\subsection{Identifying Lifestyles Based on Annual Energy Demands}

The Energy Lifestyle framework used here (Schwarzinger et al., 2019b) is based on the three-part lifestyle concept by Lüdtke (Lüdtke, 1996). The first part, Performance, focuses on the observable facts about an individual's behavior, practices and relations to their physical surroundings. In the case of Energy Lifestyles, specific patterns of "Performance" are the reason for individuals to have specific patterns of energy demand across different areas of life. Groups of individuals with similar Energy Lifestyles can then be identified by clustering people according to their estimated energy demand patterns. The second part, Situation, represents the objective context in which a lifestyle-specific behavior is conducted. It contains information on socioeconomic characteristics, cultural resources, and constraints. The third part, Mentality, focuses on psychological characteristics such as perceptions, values, and preferences. Methodologically, "Performance" is the basis for identifying and describing lifestyle groups" characteristic behaviors (and related impacts), while "Situation" and "Mentality" are essential for achieving a broader understanding about how different lifestyle groups live. This behavior-centered perspective aligns relatively well with understanding a lifestyle as a "system of classified and classifying practices" (Bourdieu, 1987).

Why is clustering respondents on the basis of estimated energy demands considered a more appropriate approach to identifying Energy Lifestyles than clustering them according to their psychological or socio-demographic characteristics? A comparison of different approaches to group identification, using the same representative dataset from 2009, showed that the former method leads to more useful results than clustering respondents according to psychological or socio-demographic characteristics (Bohunovsky et al., 2011; Schwarzinger et al., 2018). This becomes particularly relevant when groups with distinct energy behavioral patterns shall be identified and in a second step characterized by psychological and socio-demographic variables. 
As indicated above, the Energy Lifestyle concept used here (Schwarzinger et al., 2019b) distinguishes six areas of life in which individuals can behave according to their preferences and make choices with regard to the technical equipment they use or purchase ("Performance"). The six areas are "housing," "mobility," "diet," "consumption," "leisure," and "information." In each of these areas, a variety of climate- and energy-relevant goods and services can be consumed. They represent "dimensions of energy consumption." 2 To identify groups of people with similar Energy Lifestyles, individuals are clustered according to their patterns of energy consumption across these dimensions. But why are energy demands used as a proxy for energy- and climate-relevant behavior instead of GHG emissions? A person's behavior results in a certain energy demand. The link between behavior and energy demand is practically deterministic. For example, a respondent's car consumes a certain amount of fuel per distance, and the respondent drives a certain number of kilometers per year, accompanied by a certain number of people. The total amount of fuel and (under consideration of the whole supply chain of the respective fuel type) the amount of primary energy used can be calculated on the basis of these numbers by life-cycle assessment (LCA) methodology (Finkbeiner et al., 2006). When all the collected responses about behavior and equipment use are processed in this way, an estimate of each respondent's annual primary energy demand in each of the six areas of life can be obtained. These estimated annual primary energy demands (in the following referred to as simply "energy demands") appear as reasonable indicators for the energy intensity of a person's behavior in each of the six dimensions of energy consumption (or areas of life). Finally, lowering the climate impact of these lifestyles can be achieved by either reducing the behavior or generating carbon-neutral energy.

This operationalization of Energy Lifestyles also implies certain limitations. The approach was explicitly developed for the "bottom-up" grouplevel assessment of Energy Lifestyles and not as a substitute for top-down national statistics. For example, building or buying a home is often an important part of an individual lifestyle. However, (unlike, e.g., for cars) there is currently no reasonable way to estimate the energy demand for the construction of dwellings on an individual level as there is little

\footnotetext{
${ }^{2}$ Due to limited personal choice, the energy demands and emissions related to public infrastructure, emergency services, or the reception of medical treatment are not considered part of a person's lifestyle.
} 
information available on the lifespan of buildings. Thus, the methodology focuses on lifestyle-specific behavior where the associated energy demand can be attributed to with reasonable accuracy (see also Chap. 3 ).

\subsection{Data And Methods}

The dataset used in this study is based on a representative sample of the Austrian population consisting of 604 respondents. It was collected in the course of the Horizon 2020-funded project "ECHOES" in summer 2018 (together with samples from 30 other European countries) in an onlinesurvey setting in which respondents received a small monetary reward for their participation (Reichl et al., 2019). Among other tasks, a crossEuropean analysis of Energy Lifestyles was carried out with these data applying the same method of group identification as that used herein (Schwarzinger et al., 2019a).

The survey covered the three main lifestyle components of "Performance," "Situation," and "Mentality" (Lüdtke, 1996). With regard to "Performance" and "Mentality," the survey had a particular focus on energy behavior in order to enable both an LCA estimation of the energy demand resulting from individual behavior and a discussion of the role of psychological characteristics with regard to behavioral patterns. The raw dataset and questionnaire are available online ${ }^{3}$ (Reichl et al., 2019).

- Behavior ("Performance") was covered by questions related to energy- and climate-relevant behavior and equipment use in the six areas of life. The items were designed in such a way that they could be answered by normal users and consumers without special technical knowledge.

- With regard to socio-demographics ("Situation"), age, sex, urban/ rural residence, household size, number of children under 14, educational level, and subjective social status were used.

- Psychological characteristics ( Mentality") were covered by variables and scales on political orientation, beliefs regarding the implications of the spread of renewable energy sources, belief in climate change, perceived normative pressure, self-efficacy, subjective personal obligation, pro-environmental identity, intention to support the energy transition, and acceptance of energy policy measures.

${ }^{3}$ https://db.echoes-project.eu/echoes/home 
Additionally, the Energy Lifestyle framework (Schwarzinger et al., 2019b) considers "Context," which stands for specific circumstances that are associated with the country or region a respondent lives in. In the case of Austria, ZIP codes were used to define seven regions. While sociodemographic and psychological variables could be used without any uncommon transformations, data on behavior and equipment use had to be processed into estimations for the respondents' energy demands in the six areas of life.

As described in Chap. 3, an LCA-based estimation of energy demands on the basis of self-reported behavior and equipment use ("Performance") was used. It had already been conducted in the course of a cross-European study of Energy Lifestyles during the ECHOES project (Schwarzinger et al., 2019a). It was estimated separately for all surveyed activities and then summarized in the six areas of "housing," "mobility," "diet," "consumption," "leisure," and "information" (Bird et al., 2019). As the LCA estimations were made under consideration of country-specific conditions (e.g., heating/cooling degree days), they could be used for the Austriaspecific analyses without the need for further modifications.

\subsection{Multidimensional Identification OF ENERGY LIFESTYLES}

According to the Energy Lifestyle framework (Schwarzinger et al., 2019b), the annual individual energy demand in a certain area of life is a result of behavior conducted in the respective field. The estimated energy demands represent the energy intensity of activities carried out by an individual in the course of a year (as far as they are covered by the survey). In the following, the results of clustering respondents on the basis of estimated energy demands in six areas of life are presented. Socio-demographic-, psychological-, and context-related variables are used to characterize the identified groups and to obtain a holistic impression of the groups' Energy Lifestyles.

Before considering the results in detail, a short look at the aggregate level is helpful. The data represent the energy impacts associated with the lifestyle of an "average Austrian." On average, with around 39,000 and 38,000 megajoules (MJ) per year, respectively, housing and mobility are head-to-head and together account for around $70 \%$ of an average Austrian's annual energy impact. Diet accounts for around 15,000 MJ, 
leisure activities for 13,000 , consumption of durable goods and clothing for 6000 , and the acquisition of information for less than $1000 \mathrm{MJ}$ per year. At this point in time, the distribution of primary energy impacts is closely linked to the distribution of emissions. This is due to the fact that technologies using fossil fuels achieve low overall energy efficiency and at the same time are emission intensive. However, there is an important reason for the current focus on Energy Lifestyles instead of "Emission Lifestyles"- "Emission Lifestyles" cannot be identified once true decarbonization is achieved (which shall be the case by around 2050). Instead, Energy Lifestyles can continue to be analyzed even when a "zero carbon economy" has been established. Lifestyles based on emissions, however, will be presented in Chap. 8 .

The respondents were clustered on the basis of each respondent's estimated energy demand in each of the six areas of life (housing, mobility, consumption, diet, leisure, and information). As indicated above, the energy demands in the different areas show very different scales. Therefore, before being passed to a conventional and well-documented k-means clustering algorithm, they were $\mathrm{z}$-transformed. This procedure minimized the arbitrary and systematic influence on the outcome. A solution with five Energy Lifestyle clusters was chosen. It provides a reasonable balance between interpretability and level of detail for a nation-wide overview. Figure 6.1 depicts the energy demand patterns of the five groups in relation to the Austrian average (100\% baseline).

The energy demands of the five groups are composed in very different ways. Lifestyle 1 is characterized by a peak in the mobility dimension. Lifestyle 2 is below average in all dimensions. Lifestyle 3 is above average in the two dimensions leisure and information, lifestyle 4 in housing, and lifestyle 5 in consumption. For example, lifestyles 3 and 5 have overall energy demands virtually equal to the national average of about 113,000 MJ per year, but their patterns differ from each other and from "the average Austrian." Apparently, group profiles represent different variations of the expressive component ("Performance") of energy-related lifestyles.

What also becomes particularly clear in this figure is that the areas of life with the greatest mean energy demand (housing and mobility) are also the areas with the greatest relative differences between the groups. Diet, in contrast, shows a remarkably small variation between groups. This is an indication that the type (and thus the energy intensity) of an individual's diet barely corresponds with energy-related behavior in other areas of life. 


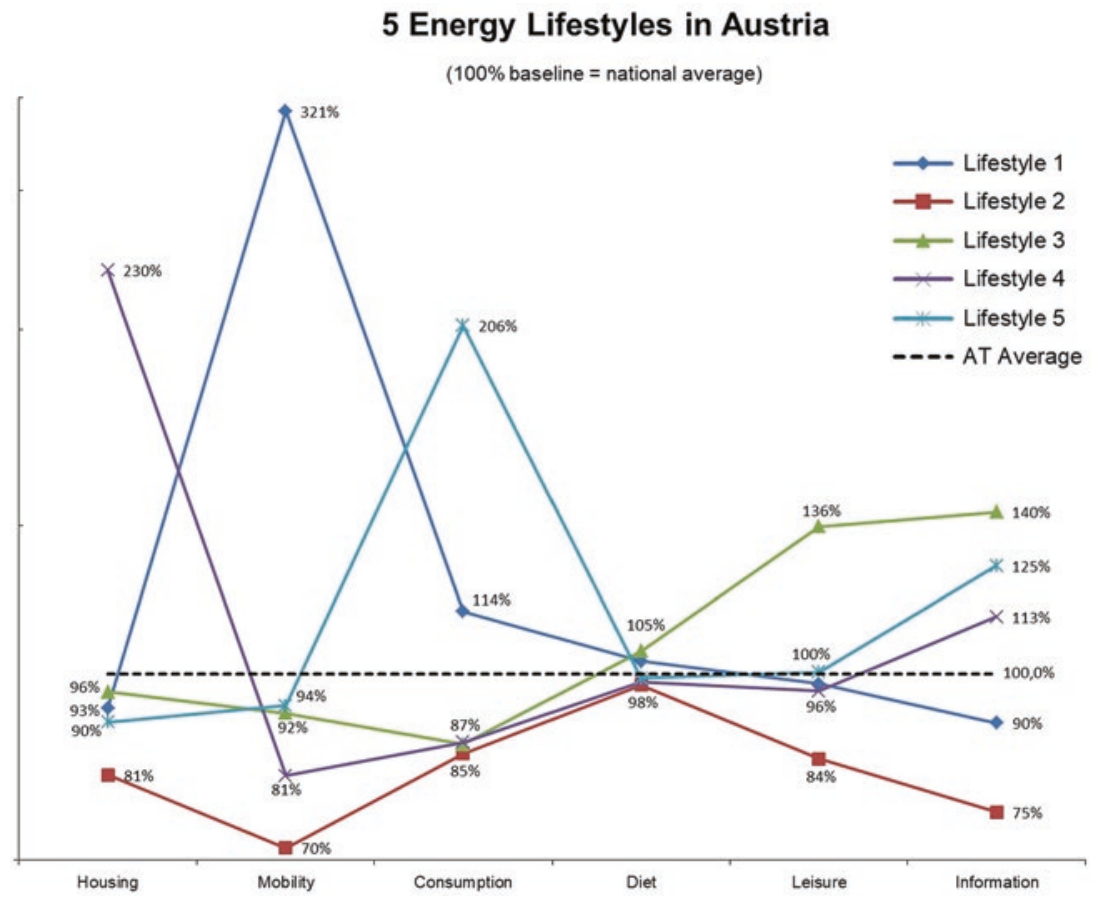

Fig. 6.1 Energy demand profiles of five Energy Lifestyle groups in Austria. (Source: Calculation based on ECHOES data [Reichl et al., 2019])

Consumption, the area of life with the fourth largest average share of individual overall primary energy demand, shows relatively large differences between the groups, while leisure as well as information show slightly smaller differences between groups.

\subsection{Energy Lifestyle Groups and their Role IN THE ENERgY Transition}

Table 6.1 provides a summary of the overall energy demand of each lifestyle group as well as information on the manifest living conditions ("Situation" and "Context") and the perceptions, norms, and beliefs of respondents in the identified groups ("Mentality"). These characterizations are also based on correspondence analyses and provide various 


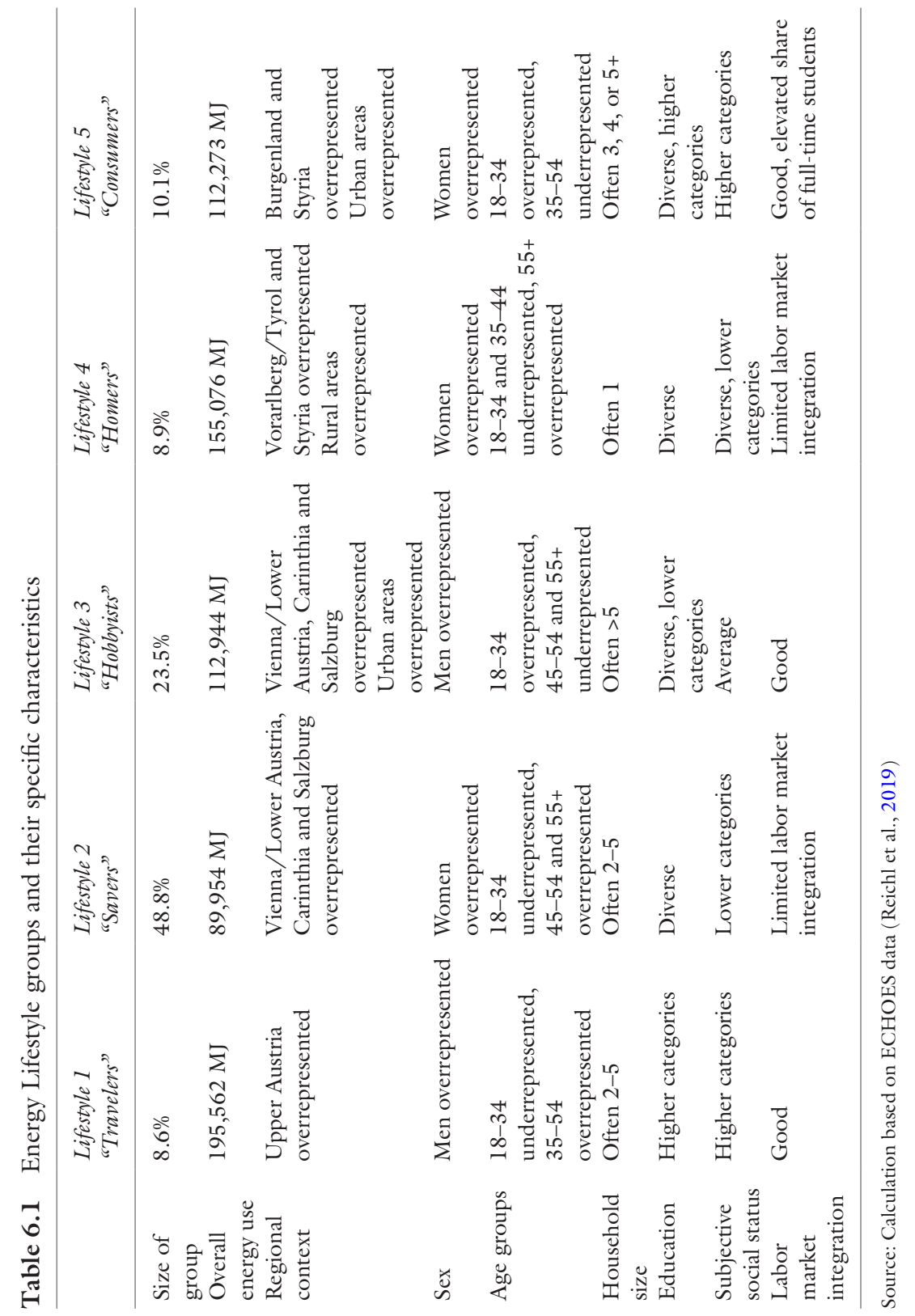


insights into the lifestyles typical for the respective groups. Moreover, they provide potential starting points for group-specific policy measures toward a lower energy- and climate-related impact.

\section{Energy Lifestyle 1: "Travelers"}

Energy Lifestyle 1 is characterized by an average overall energy demand of approximately 196,000 MJ per year. A total of 8.6\% of all Austrian survey respondents were assigned to this group on the basis of their patterns of energy demand. Respondents from Upper Austria are overrepresented in this group. Men and people between the ages 35-54 are overrepresented, while respondents between 18 and 34 are underrepresented. There is a tendency toward larger households and large living spaces per capita. Together with an above-average share of fossil-fueled heating systems, this results in the third highest energy demand for "housing." A tendency toward higher education can be observed. Right political orientation is overrepresented. Furthermore, there is a tendency toward a higher subjective social status. Many respondents report good labor market integration by being either self-employed or employed 30 hours per week or more. In "mobility," this group is characterized by an outstandingly high energy demand of $320 \%$ of the Austrian average. This is a result of extraordinarily long annual driving distances, much air travel and little use of public transport. Although the share of hybrid-electric and fully electric cars is higher than in the Austrian average, their share is not high enough to result in a considerable decrease in mobility-related energy demand on the group level. The group is partially interested in car sharing or has already tried and liked it. However, the question arises as to how well car sharing is compatible with the tendency toward high annual driving distances. Regular bicycle use is not very common, whereas the proportion of respondents who use the bicycle "sometimes" is elevated. The slightly above-average energy demand for "consumption" is a result of a tendency toward higher consumption activity in both fashion and electronics. Despite some meatorientation in the group-specific dietary preferences, these preferences are not so common as to lead to an elevated energy demand. Regarding leisure activities, there is an above-average share of activities that require a moderate amount of equipment and infrastructure, while activities with more extensive needs are underrepresented. Although there is a tendency toward an increased use of electronics, the group has a below-average energy demand for "information." This corresponds well with a high share of electricity from renewable energy production. 
Overall, this group generally shows a tendency toward intensive consumption and energy-intensive practices. Technically, there are potentials for modernization (e.g., the current overrepresentation of fossil-fueled heating systems) and indications for interest in sustainable technologies (e.g., overrepresentation of hybrid-electric and electric vehicles). On the one hand, disbelief in climate change and small scores in environmental identity as well as in the perceived normative pressure to act in accordance with the energy transition are more frequent than in the Austrian average. Additionally, the intention to support the energy transition is small. On the other hand, lifestyle 1 respondents have a tendency toward high selfefficacy with regard to the energy transition and often strongly agree with the statement that renewables will create new jobs. With regard to enabling this group toward the energy transition, intrinsic factors do not appear to be a suitable starting point for policy interventions. By contrast, linking the energy transition with the consumption of innovative technologies and related economic opportunities might be a more suitable strategy.

\section{Energy Lifestyle 2: "Savers"}

Energy Lifestyle 2 is characterized by an average overall energy demand of approximately 90,000 MJ per year. In total, 48.8\% of all Austrian survey respondents were assigned to this group on the basis of their patterns of energy demand. Respondents from Vienna/Lower Austria, Carinthia, and Salzburg are overrepresented in this group, while Styria and Burgenland are underrepresented. Women and age groups 45 and above are overrepresented, whereas respondents between 18 and 34 are underrepresented. Similar to lifestyle 1, there is some tendency toward larger households but with smaller living space categories. This, in combination with a higher share of modern heating systems, results in the lowest group-specific energy demand for "housing." Regarding education, there is a diverse overall picture in the group. Compared to the Austrian average, respondents show a tendency toward reduced labor market integration and often describe their social status as "below average."

In the area "mobility," the group also has the lowest energy demand of all groups (69.7\% of the Austrian average). This reflects their small annual driving distance and an above-average use of public transport. Furthermore, it reflects a lower number of private flights. The picture with regard to car sharing is diverse, with some indication of interest in this subject. In this context, it might be interesting to determine which individuals are 
particularly open and interested. If car sharing allows people to give up owning a car, this can be accompanied by energy savings and ecological benefits. However, if trips that are currently made by public transport are shifted to the car as a result of car sharing, the ecological effect is likely to be negative. As in lifestyle 1 , regular bicycle use not very common. Also in the area of "consumption," lifestyle 2 group members have the lowest primary energy demand of all groups. This reflects a tendency toward modest consumption behavior in both fashion and electronics.

Although there is an above-average share of respondents with reduced meat consumption, the dietary preferences and impacts as a whole are again hardly group-specific. The leisure activities of respondents assigned to this group cause the lowest energy demand of all groups. Activities that require limited amounts of equipment and infrastructure are overrepresented. With regard to electronics, there is a tendency toward low usage in combination with an overrepresentation of "green electricity," which is reflected in the fact that the group also has the lowest average energy demand for "information."

This group accounts for nearly half of the sample. It has the lowest overall energy demand of all identified groups and a below-average energy demand in all six areas of life. A relatively large share of respondents has a high self-efficacy with regard to the energy transition, a pro-environmental self-identity, and the intention to support the energy transition. Many in the group see it as a personal obligation to be energy efficient and to behave in accordance with the energy transition. Many would accept policy measures that result in higher costs. However, social status and labor market integration indicate that the small energy impact among this group is not only a consequence of conscious decisions regarding energy use but also a result of economic restrictions. In addition to the aforementioned tendency toward pro-environmental positions, there is also an aboveaverage rejection of the statement that renewables are good for the environment, which might be an indication of the existence of subgroups with diverging positions.

Although the group has very low energy demands, the nation-wide potential of a more systematic implementation of energy-efficient technologies within lifestyle 2 should not be underestimated due to the large size of the group. In order to develop target-oriented policy measures (e.g., funding for the acceleration of costly technological upgrades), a more detailed exploration within the group seems helpful because the information at hand leaves relatively much room for speculation. 


\section{Energy Lifestyle 3: "Hobbyists"}

Individuals with Energy Lifestyle 3 have an average overall energy demand of approximately 113,000 MJ per year. In total, 23.5\% of all Austrian survey respondents were assigned to this group on the basis of their patterns of energy demand. Respondents from Vienna/Lower Austria, Carinthia, and Salzburg are overrepresented in the group, while Styria, Burgenland, and Upper Austria are underrepresented. Men and ages 18-34 are overrepresented, whereas respondents of 45 years and above are underrepresented. There is a tendency toward large households of more than five people and smaller living space categories. This, in combination with a higher share of fossil-fueled heating systems and an overrepresentation of blocks with more than ten dwellings, results in a "housing"-related energy demand that is slightly below the national average. Regarding education, the overall picture is diverse, with some tendency toward lower levels. Left political orientations are overrepresented. Compared to the Austrian average, respondents tend to show good labor market integration and often see their social status as "average."

Regarding "mobility," this group is characterized by a below-average energy demand. This reflects the high share of close-to-average annual driving distances and a diffuse overall picture with regard to air travel. There is a tendency toward low usage of public transport and little interest in car sharing. The group shows a diverse picture regarding bicycle use but also an above-average share of all-season cyclists. The below-average energy demand for "consumption" results from a tendency toward reduced consumption activity in fashion and an above-average share of respondents who "like to always have the latest technology" in electronics. Despite an overrepresentation of meat-oriented respondents, the "diet"related energy demand is again close to the average. Regarding leisure activities, there is an above-average share of activities that require an elevated to high amount of equipment and infrastructure, which leads to the highest average energy demand for "leisure" of all five groups. There is a tendency toward an intensive use of electronics. The above-average energy demand for "information" reflects the combination of an intensive use of electronics and a below-average share of respondents who reported using "green electricity."

In sum, this group is practically average with regard to the overall primary energy demand. The distribution across the six areas of life shows, however, an elevated energy demand for leisure activities and use of 
electronic means for information acquisition. Although this group appears relatively unremarkable with regard to energy impacts at first glance, a closer look reveals considerable potential for technological modernization. With an overrepresentation of fossil energy sources, there are clear limits to a further reduction of energy demand and related GHG emissions. Thus, target group-specific measures aiming at technology change also appear reasonable in this group. At the moment, small impacts seem to be mostly a consequence of small-to-moderate usage intensity. However, this limited usage intensity appears not to be related to explicit personal intentions or pro-environmental self-identity but instead caused by other factors. Lifestyle 3 respondents show relatively often a low self-efficacy with regard to the energy transition, which might further reduce their motivation to change personal behavior or technology choices. On the one hand, labor market and social status give reason to assume that this group can afford technological upgrades more easily than other groups. On the other hand, the willingness to do so could be questionable.

\section{Energy Lifestyle 4: "Homers"}

Energy Lifestyle 4 shows an average overall energy demand of approximately $155,000 \mathrm{MJ}$ per year. A total of $8.9 \%$ of all Austrian survey respondents were assigned to this group on the basis of their patterns of energy demand. Respondents from Vorarlberg/Tyrol and Styria are overrepresented in this group, while Upper Austria and Salzburg are underrepresented. Women and the ages 55+ are overrepresented, whereas 18-34 and 35-44 are underrepresented. There is a tendency toward smaller and single-person households without children. Large living space categories and rural housing types such as single-family homes are overrepresented. This, in combination with an elevated share of non-up-to-date heating technologies, results in the group having by far the highest average "housing"-related energy demand of all groups (320\% of the Austrian average). Regarding education, the overall picture is diverse, and this group shows a tendency toward limited labor market integration. With regard to political orientation, center to center-right positions are overrepresented. There is a diverse picture of the subjective social status, with an elevated share of respondents who describe their situation as "worst off."

In "mobility," group members have a below-average energy demand. This reflects a high share of very small annual driving distances and a diverse overall picture with regard to air travel. There is some indication 
for openness toward more efficient car propulsion technologies (plug-in hybrid), whereas the share of hybrid-electric and fully electric vehicles is smaller than in the Austrian average. There is indication for little interest in car sharing, but also indication for openness toward public transport. Regarding bicycle use, this group shows very diverse behavior, with a tendency toward limited usage. The below-average energy demand for "consumption" reflects a tendency toward average or reduced consumption in fashion and a tendency toward reduced consumption in electronics. Despite a tendency toward reduced meat consumption, the overall picture of group-specific "diet"-related energy demand is again close to the average. Regarding "leisure" activities, there is an above-average share of activities that require a moderate amount of equipment and infrastructure, which results in the group having a below-average primary energy demand for "leisure." There is evidence for a limited use of electronics. Despite this, they have an above-average energy demand for "information," which is associated with the below-average share of respondents who use "green electricity."

In general, an intrinsic motivation seems to play only a minor role in potential upgrading decisions. Many respondents in this group strongly disagree with the intention to support the energy transition, and this group has an above-average share of respondents who do not believe in climate change. They often do not perceive any normative pressure to act in a way that would result in a lower energy demand, and they have low values in self-efficacy with regard to the energy transition. Concerning the possible creation of new jobs through the spread of renewable energy systems, strong disagreement is relatively often reported. Furthermore, this group shows a tendency toward little acceptance for costly policy measures. In view of the overall picture, financial incentives (especially for building-related upgrades) could be a starting point for a group-specific strategy.

\section{Energy Lifestyle 5: "Consumers"}

Energy Lifestyle 5 has an average overall energy demand of approximately $113,000 \mathrm{MJ}$ per year. In total, 10.1\% of all Austrian survey respondents were assigned to this group on the basis of their patterns of energy demand. Respondents from Burgenland and Styria are overrepresented in Energy Lifestyle 5, while Vienna/Lower Austria, Carinthia, and Salzburg are underrepresented. Women and ages 18-34 are overrepresented, whereas 
ages $35-54$ are underrepresented. There is a tendency toward larger households. A high share of small living space and an elevated share of urban/suburban dwelling types are characteristic for this group. Although the picture regarding heating systems is diverse, the average "housing"related energy demand of this group is below the national average. Regarding education, the overall picture is diverse, with some tendency toward higher education. Center-left political orientations are overrepresented. An above-average share of full-time students and respondents with good labor market integration is shown. Respondents reported a relatively high subjective social status.

Similar as respondents from lifestyle 3 , respondents show a practically average overall energy impact, but they have a clearly distinct profile. In "mobility," this group is characterized by a slightly below-average energy demand. This reflects a high share of small-to-average annual driving distances and a diverse overall picture with regard to air travel. There is a tendency toward cars with higher efficiency propulsion systems. There is some indication for openness toward the use of public transport and some evidence for interest in and positive experience of car sharing. The group shows diverse behaviors regarding bicycle use but also an above-average share of all-season cyclists. The strongly above-average energy demand for "consumption" is a result of this group's tendency toward elevated or intensive consumption of fashion and electronics. Despite a meat-reduced overall picture of the group-specific "diet," the associated energy demand is again close to the average. Regarding "leisure" activities, there is an above-average share of activities that require a moderate amount of equipment and infrastructure, which results in this group having a "leisure"related primary energy demand practically equal to the national average. The tendency toward an intensive use of electronics in combination with a below-average share of respondents using "green electricity" results in an above-average energy demand in the area of "information."

Lifestyle 5 has an above-average share of respondents who strongly agree with the statement that renewable energy systems are good for the environment, which matches with an overrepresentation of people who believe in climate change. Although many respondents reported to perceive normative pressure, it is not so common amongst members of this group to see it as a personal obligation to be energy efficient and to behave in accordance with the energy transition. Additionally, a moderate tendency to disagree with supporting the energy transition can be observed. However, there is also a slight overrepresentation of respondents who 
show higher self-efficacy with regard to the energy transition. In total, environmentally conscious consumption seems to already play some role in this group. This is, for example, supported by the overrepresentation of hybrid-electric and electric cars owned by respondents from this group.

\subsection{Conclusions And Outlook}

This chapter started from the assumption that an Energy Lifestyle is multidimensional. Using an energy-specific lifestyle method (Schwarzinger et al., 2019b), five Austrian Energy Lifestyles with distinct patterns in their energy-related behavior were identified. It turned out that there is no group with behavioral patterns that are even close to the "average Austrian." This is in line with findings on the European level, where no "average Europeans" could be identified in a relevant number. As found in an earlier study with an Austrian dataset from 2009 (Schwarzinger et al., 2018), "mobility," again, turned out to play a crucial role for Energy Lifestyles by showing the largest relative difference in energy demand between the groups. A similarly massive impact of "mobility" was found in a Europe-wide view (Schwarzinger et al., 2019a).

The five Energy Lifestyles identified in Austria were characterized in detail using the results of correspondence analyses. This reduction in complexity led to a relatively tangible picture of the Energy Lifestyle groups and their potential role in the energy transition. In most cases, groupspecific behavior within and across different areas of life could be reasonably interpreted. Some examples for potential group-specific policy measures could be discussed for most groups, while, for example, in the case of lifestyle 2, the overall picture was less tangible, and a need for further research became evident. In general, this explorative methodology provided an overview with regard to the Austrian population that appears to be more useful than the typologies based on psychometric lifestyle models used in the past (Hierzinger et al., 2011; Bohunovsky et al., 2011).

Lifestyle-specific behavioral patterns, on the one hand, and sociodemographic and psychological characteristics, on the other hand, were put into relation with each other on the basis of the over- and underrepresentation of attributes in the individual groups. This approach takes into account that there is usually little statistical relationship between behavior and single explanatory variables when controlling for other variables (Kollmuss \& Agyeman, 2002; Csutora, 2012; Newton \& Meyer, 2013). The underlying causes for living a certain Energy Lifestyle can 
accordingly be manifold, and complex constellations of influencing factors might play a role. Using variables with an unreliable link to behavior as indicators for group membership might be a reason why earlier studies on Energy Lifestyles in Austria achieved less useful results and identified groups with relatively similar behavioral patterns.

The approach described here enhances the previous understanding of Energy Lifestyles by providing a reasonable and plausible overview of Energy Lifestyles in Austria. With regard to future research, it provides indications of where it could be worth taking a closer look in subsequent studies. The results presented show that an isolated view on single behavioral dimensions is at risk of not sufficiently considering the relationships between different behavioral domains. Furthermore, converting individual and group-specific behaviors into the "currency" of estimated primary energy demands (which is uncommon in sociology) makes the methodology a suitable basis for interdisciplinary cooperation, as has been demonstrated in the Horizon 2020 Project ECHOES.

When it comes to target areas for policy measures aiming at an effective reduction of energy demand and emissions on a national level, there is enormous potential for improvement in the energy-intensive areas of "mobility" and "housing." These sectors are those in which fossil fuels (and thus emission-intensive technologies) still play a major role. These priorities are hardly surprising and already part of strategies focusing on the technological transition toward zero-emission technologies. Despite the relatively strong focus on these two energy-intensive areas of life, the policy design for the five target groups poses the following very heterogeneous challenges:

In Energy Lifestyle 1, the group with the extraordinary high energy demand for "mobility," intrinsic factors do not seem to play a relevant role. Instead, linking the energy transition with the consumption of innovative technologies and related economic opportunities might be a more suitable strategy to engage this group in the energy transition. Energy Lifestyle 2, the largest group, which makes up almost half of the population, has a clearly lower average energy impact than the national average. However, this does not mean that this group should be disregarded in energy efficiency strategies. If the behavior and technological equipment of this group remain unchanged while the energy efficiency in the other groups increases, Energy Lifestyle 2 is likely to become problematic in terms of an "above-average" energy demand in the course of a few years. In the case of Energy Lifestyle 3, there is possibly an even greater risk that 
the group is considered unremarkable and overlooked due to its currently "average" energy demand. However, the group's impact is kept at this (from today's perspective) "average" level only by relatively low usage intensity. While the affordability of technological upgrades seems to be given, the motivation for environmentally sustainable consumption is low. The fact that respondents from 18 to 34 are overrepresented in this group draws special attention to group-specific long-term strategies. With regard to Energy Lifestyle 4, "Homers," potentials for energy savings might be accessed in particular through financial incentives for technological upgrades in the area of housing. However, an overrepresentation of single-person households and rural building types might be limiting factors for efficiency gains, posing a particular challenge to the design of energy strategies. Similar to respondents from Energy Lifestyle 3, "Hobbyists," respondents with Energy Lifestyle 5, "Consumers," have an average energy demand close to the Austrian national average. Remarkably, environmentally conscious consumption and practices, especially in the area of "mobility," already play a certain role for this group and might be taken into consideration for specific policy strategies.

Of course, these policy potentials only represent a small fraction of the considerations that need to be taken into account in the preparation of nation-wide energy efficiency and decarbonization strategies. However, with the exploration of five Energy Lifestyles in Austria, a basis for a better understanding of affected target groups' life realities could be achieved. The better an individual's specific needs can be taken into account, the more likely it is to improve their engagement in the energy transition, and the higher the chance is to reconcile energy efficiency, social sustainability, public acceptance, and economic feasibility. The next chapter thus will consider individuals' obstacles to change and the gap between their attitudes and behaviors.

\section{REFERENCES}

Bird, D. N., Schwarzinger, S., Kortschak, D., Strohmaier, M., \& Lettmayer, G. (2019). Report: A detailed methodology for the calculation of cumulative energy demand per survey respondent. The ECHOES Consortium.

Bohunovsky, L., Grünberger, S., Frühmann, J., \& Hinterberger, F. (2011). Energieverbrauchsstile Datenbank zum Energieverbrauch österreichischer Haushalte: Erstellung und empirische Überprïfung. Endbericht. 
Bourdieu, P. (1987). Distinction: A social critique of the judgement of taste. University Press.

Csutora, M. (2012). One more awareness gap? The behaviour-impact gap problem. Journal of Consumer Policy, 35, 145-163.

Finkbeiner, M., Inaba, A., Tan, R., Christiansen, K., \& Klüppel, H.-J. (2006). The new international standards for life cycle assessment: ISO 14040 and ISO 14044. The International Journal of Life Cycle Assessment, 11, 80-85.

Hierzinger, R., Herry, M., Seisser, O., Steinacher, I., \& Wolf-Eberl, S. (2011). Energy Styles. Klimagerechtes Leben der Zukunft-Energy Styles als Ansatzpunkt für effiziente Policy Interventions. Endbericht zum Projekt Energy Styles. Klimaund Energiefonds.

Kollmuss, A., \& Agyeman, J. (2002). Mind the gap: Why do people act environmentally and what are the barriers to pro-environmental behavior? Environmental Education Research. Routledge, 8, 239-260.

Lüdtke, H. (1996). Methodenprobleme der Lebensstilforschung. Probleme des Vergleichs empirischer Lebensstiltypologien und der Identifikation von Stilpionieren. In O. G. Schwenk (Ed.), Lebensstil zwischen Sozialstrukturanalyse und Kulturwissenschaft (pp. 139-163). VS Verlag für Sozialwissenschaften.

Newton, P., \& Meyer, D. (2013). Exploring the attitudes-action gap in household resource consumption: Does "environmental lifestyle" segmentation align with consumer behaviour? Sustainability, 5, 1211-1233.

Reichl, J., Cohen, J., Kollmann, A., Azarova, V., Klöckner, C., Royrvik, J., Vesely, S., Carrus, G., Panno, A., Tiberio, L., Fritsche, I., Masson, T., Chokrai, P., Lettmayer, G., Schwarzinger, S., \& Bird, N. (2019). International survey of the ECHOES project. Zenodo.

Schwarzinger, S., Bird, D. N., \& Hadler, M. (2018). The "Paris lifestyle"Bridging the gap between science and communication by analysing and quantifying the role of target groups for climate change mitigation and adaptation: An interdisciplinary approach. In W. Leal Filho, B. Lackner, \& H. McGhie (Eds.), Addressing the challenges in communicating climate change across various audiences (pp. 375-397). Springer International Publishing.

Schwarzinger, S., Bird, D. N., Lettmayer, G., Henriksen, I. M., Skjølsvold, T. M., Olaeta, X. U., Alvarez, L. P., Velte, D., Iturriza, I. J., Biresselioglu, M. E., Demir, M. H., Dimitrova, E., Tasheva, M., Tiberio, L., Panno, A., Carrus, G., \& Costa, S. (2019a). Comparative assessment of European energy lifestyles. ECHOES Project Consortium.

Schwarzinger, S., Bird, D. N., \& Skjølsvold, T. M. (2019b). Identifying consumer lifestyles through their energy impacts: Transforming social science data into policy-relevant group-level knowledge. Sustainability, 11 . 
Open Access This chapter is licensed under the terms of the Creative Commons Attribution 4.0 International License (http://creativecommons.org/licenses/ by $/ 4.0 /$ ), which permits use, sharing, adaptation, distribution and reproduction in any medium or format, as long as you give appropriate credit to the original author(s) and the source, provide a link to the Creative Commons licence and indicate if changes were made.

The images or other third party material in this chapter are included in the chapter's Creative Commons licence, unless indicated otherwise in a credit line to the material. If material is not included in the chapter's Creative Commons licence and your intended use is not permitted by statutory regulation or exceeds the permitted use, you will need to obtain permission directly from the copyright holder. 